\title{
LUKSUZNI REZIDENCIJALNI OBJEKAT SA PRIKAZOM ENTERIJERA U DIMOTSE NASELJU U BOCVANI
}

\section{LUXURY RESIDENTIAL BUILDING WITH THE INTERIOR DESIGN IN DIMOTSE SETTLEMENT IN BOTSWANA}

\author{
Milica Gruban, Fakultet tehničkih nauka, Novi Sad
}

\section{Oblast - ARHITEKTURA}

Kratak sadržaj - Kroz ovaj rad ostvaren je spoj teorije $i$ prakse. Tema je stvaranje luksuznih rezidencijalnih objekata, koji svoje korene vuku iz klasične arhitekture, kao izvor večne uzvišene lepote.

Ključne reči: Luksuzna arhitektura, arhitektura stanovanja, arhitektura za odmor, fleksibilni i modularni objekat

\begin{abstract}
The aim of this research was to design luxury residential buildings using main principles that are used in classical architecture (essential elements) and connect it with eastern architectural world. To connect material and immaterial world, to work with contrast and find a balance between them. The building is situated in Dimotse Paradise village in Botswana and it was of the huge importance that the building is flexible and modular so there is a possibility of creating a large number of variations. From the urbanistic point of view, the inverse method is used, to start with the building, make its variations and define urbanistic contexst. In the interior the idea was to demonstrate that it is not so important how much space we have, but how it is organized and that by using luxury furniture, the space gets a note of luxury. However, in the first place, it is an architecturally highquality space, functional, to satisfy human needs that are changing, which is why flexibility is extremely important.
\end{abstract}

Keywords: Luxury architecture, residential architecture, vocational architecture, flexible and modular building

\section{UVOD}

Cilj ovog istraživanja bio je dizajnirati luksuzne stambene zgrade koristeći glavne principe koji se koriste u klasičnoj arhitekturi (esencijalni elementi) i povezati je sa istočnim arhitektonskim svetom. Povezati materijalni i nematerijalni svet, raditi sa kontrastom i pronaći balans između njih. Zgrada se nalazi u Dimotse Paradajs naselju u Bocvani i bilo je od velike važnosti da je zgrada fleksibilna i modularna, tako da postoji mogućnost kreiranja velikog broja varijacija. Sa urbanističkog stanovišta, koristi se inverzna metoda gde se počinje od zgrade, kreiraju njene varijacije i definiše urbanistički kontekst.

\section{NAPOMENA:}

Ovaj rad proistekao je iz master rada čiji mentor je bila dr Ivana Miškeljin.
U enterijeru je ideja bila pokazati da nije toliko važno koliko prostora imamo, već kako je organizovan i da koristeći luksuzni nameštaj prostor dobija notu luksuza. Ipak, na prvom mestu je arhitektonski kvalitetan prostor, funkcionalan, da zadovolji čovekove potrebe koje se menjaju, zbog čega je fleksibilnost od izuzetne važnosti.

\section{OBLAST ISTRAŽIVANJA}

\section{Poređenje fleksibilnosti luksuznih stambenih zgrada kroz istoriju:}
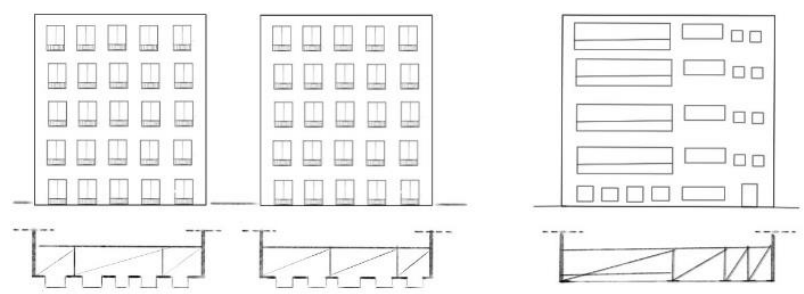

Slika 1. Klasična zgrada, levo, koja pokazuje fleksibilnost u funkciji nasuprot savremenoj zgradi, desno, gde je mnogo teže praviti prenamenu objekta. Ideja razvijena sa prof. Marijom Rosom Cerverom Sardom

Gledajući fasadu ne može se decidno utvrditi koja je bila funkcija zgrade, oblik je važan i funkcija sledi oblik, što znači da se funkcija može lako promeniti. Na fasadi možemo uočiti ritam koji se postiže fenestracijom. Ujednačeni ritam omogućava izvesnu fleksibilnost. Objekti su izrađeni u idealnim proporcijama, organizaciji na fasadi, simetriji i ritmu. Klasični svet nije dizajniran iz funkcije, već iz hijerarhije, protokola i reprezentativnosti. Forma je na prvom mestu, a funkcija sledi formu. Savremeni pokret je nastao definišući funkcije, što znači da ako je neko mesto planirano da bude dnevna soba ili kuhinja, to ne može biti ništa drugo. U modernoj arhitekturi forma sledi funkciju, zbog čega je nastala fenestracija bez ritma i objekti su jako plastični, bez mnogo mogućnosti za promenu, nefleksibilni.

Otvoreni plan izazvao je potrebu za uklanjanjem zidova u unutrašnjosti, što je dovelo do razmišljanja o novom, fleksibilnijem sistemu.

Dakle, ideja da se implementiraju klizni zidovi ili da se koristi nameštaj i tepisi kako bi se precizno identifikovale i definisale zone su odgovori o tome kako odvojiti prostor, ali da istovremeno ostane nepodeljen, fleksibilan za bilo kakve promene koje želimo. 


\section{$\underline{\text { Klasični svet }}$ \\ Vs. \\ $\underline{\text { Savremeni svet }}$ \\ FORMA \\ FUNKCIJA}

\section{PRISTUP TEMI}

Tradicionalna orijentalna arhitektura i njen uticaj na zapadni svet arhitekture:

Najveća svrha ovog istraživanja je pronalaženje veze između zapadnoevropske $\mathrm{i}$ istočne arhitekture $\mathrm{i}$ uspostavljanje simbioze između dve vodeće svetske filozofije - one koja ima materijalnu vrednost (zapadna) i one koja se zasniva na duhovnim vrednostima (istočna).

Istočna kultura prihvata gledište da je život promenjiv, da je sve energija i da se stalno pretača iz jednog u drugi oblik. Istočni svet se zasniva na duhovnom, ne na materijalnom kao zapadni svet.

Upravo iz te filozofije proizilaze i osnovni principi projektovanja koja se najviše ogleda u izboru materijala. Istočnom čoveku je važno da je objekat za jednu generaciju i svako sebi pravi svoj dom.

Materijal je drvo i samim tim je trošan, podrazumeva proces negovanja i čuvanja, te obnavljanja i održava duh prolaznosti. U zapadnoj filozofiji je akcenat na trajnosti, na kvalitetu, neprolaznosti. Zbog toga su osnovni materijali kamen i opeka, masivni sistem. Zapadni svet se bazira na principima trajnosti, čvrstim materijalima i filozofiji da bi predmeti trebali da nadžive ljude i da ostanu kao trag nečijeg života, nešto što preci ostavljaju svojim potomcima u nasleđe, imanje koje se prenosi kroz generacije.

Sa druge strane istočni svet je zasnovan na prolaznosti, fluidnosti i održivosti. Ovo pokazuje da je arhitektura istoka jako fleksibilna i prilagodiva i uči nas da je sve promenjivo i da se čovekove potrebe menjaju iz dana u dan, uči nas da prihvatamo promene, a ne da im se odupiremo.

Zapadni čovek lepotu pronalazi u stvarima oko sebe, dok istočni čovek lepotu pronalazi u sebi. Zapadni čovek prikuplja stvari, uzima mermer, zlato, drago kamenje, dok se istočni čovek oslobađa stvari.

On uživa u atmosferi i zvuku kiše, u prozračnosti prostora, u praznini. Zapravo i prazan prostor "el vacio" [1] je definisan svojom prazninom, minimalizam je tu da bi nam uprostio život i olakšao savremenog čoveka koji postaje kao nomad i često se seli, putuje na razna mesta i ima drugi vid života.

\section{PRAKTIČNI DEO - PROCES PROJEKTOVANJA}

\section{Luksuzni rezidencijalni objekat za Dimotse Paradise naselje, Gweedore estate}

Hemingvej je u svojoj knjizi Green Hills of Africa napisao „Sve što sam želeo jeste da se vratim u Afriku. Nismo je još napustili, ali kada bih se probudio u toku noći leškario bih, slušajući, nostalgičan za njom."

\subsection{Koncept}

Razlog zbog kojeg je odlučeno da se napravi objekat u Africi jeste ljudska potreba da istraži nepoznato i oseti nešto drugačije. Ovo mesto predstavlja neočekivano, nešto do sada neviđeno. Luksuzna Evropska arhitektura u sred Afrike. Očekivalo bi se da je objekat u Afričkom stilu, ali da bi se više privukla pažnja, da bi se Evropljani osećali kao kod kuće, a da bi ostali turisti imali neko novo iskustvo, odlučeno je da bude u Evropskom stilu.

Zadatak je projektovati jednu po jednu zgradu za ovo naselje, tako da će zgrada koja će biti urađena u ovom delu biti luksuzna moderna stambena zgrada sa raznim vrstama stanova. Objekat je koncipiran kao luksuzni rezidencijalni objekat za odmor, gde može da se živi preko cele godine, ali isto tako može da se dolazi periodično (zbog sadržaja koje bi naselje nudilo i kongresa, skupova koji su planirani u ovom naselju), a isto tako može da se iznajmljuje na par dana (najviše predviđeno za garsonjere $\mathrm{i}$ jednosobne stanove).

Na objektu treba da se uspostave ritam, simetrija i hijerarhija, osnovni elementi klasične arhitekture. Ritmičnost fasade je jednostavno postići fenestracijom, ukoliko je skeletni sistem. Pošto je u pitanju rezidencijalni objekat za odmor, bitno je da se uspostavi odnos otvorenog i zatvorenog prostora u objektu, odnosno odnos stana i terasa.

Otvoreni prostor svakako treba da bude manje površine od stana, ali značajno će uticati na kvalitet stanova. Glavna karakteristika ove zgrade jeste njena fleksibilnost koja se može postići pravilnim postavljanjem skeletnog sistema, slika 2.

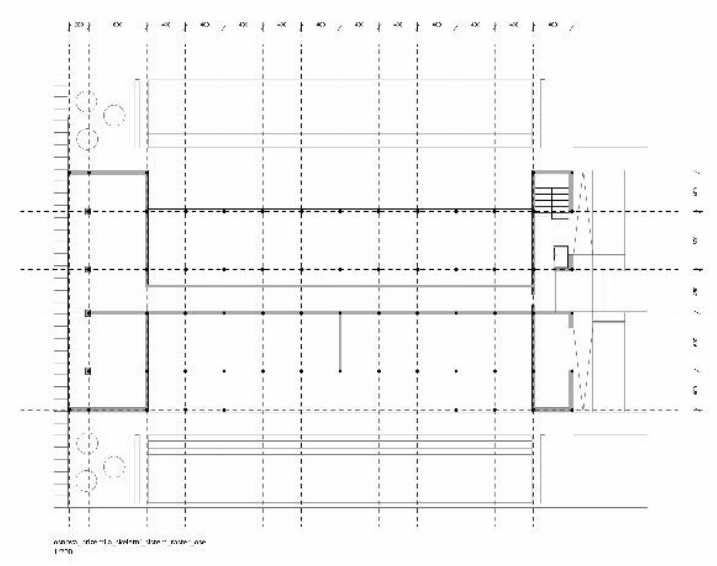

Slika 2. Osnova sa osama i rasterom konstrukcije

\subsection{Modularnost objekta $i$ varijacije stanova:}

Kada je objekat podeljen rasterski na polja, postaje veoma fleksibilan i jednostavan za prostornu organizaciju.

U toku procesa projektovanja ispitivana je fleksibilnost objekta $\mathrm{i}$ utvrđeno je da je objekat izuzetno fleksibilan i da je zgrada modularna, slika 3 .

Primer Sheme varijacija i modularnosti objekta pokazuje da je objekat modularan i da može da se poveća ili skrati u horizontali, slika 4. 


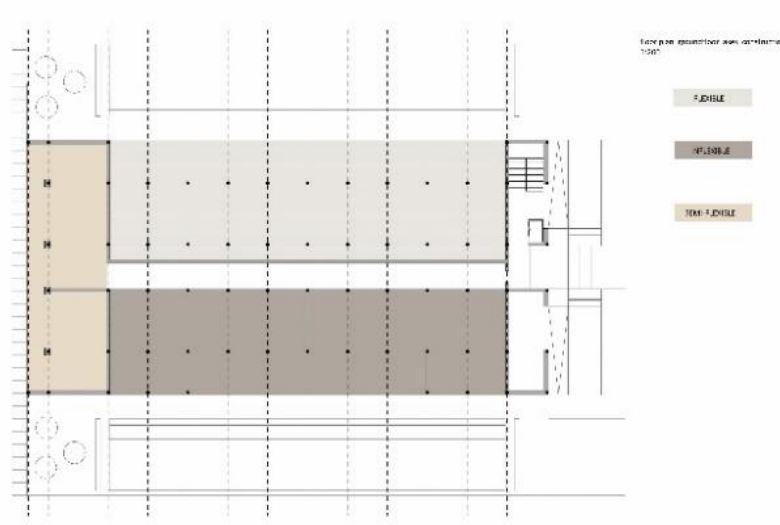

Slika 3. Ispitivanje fleksibilnosti objekta
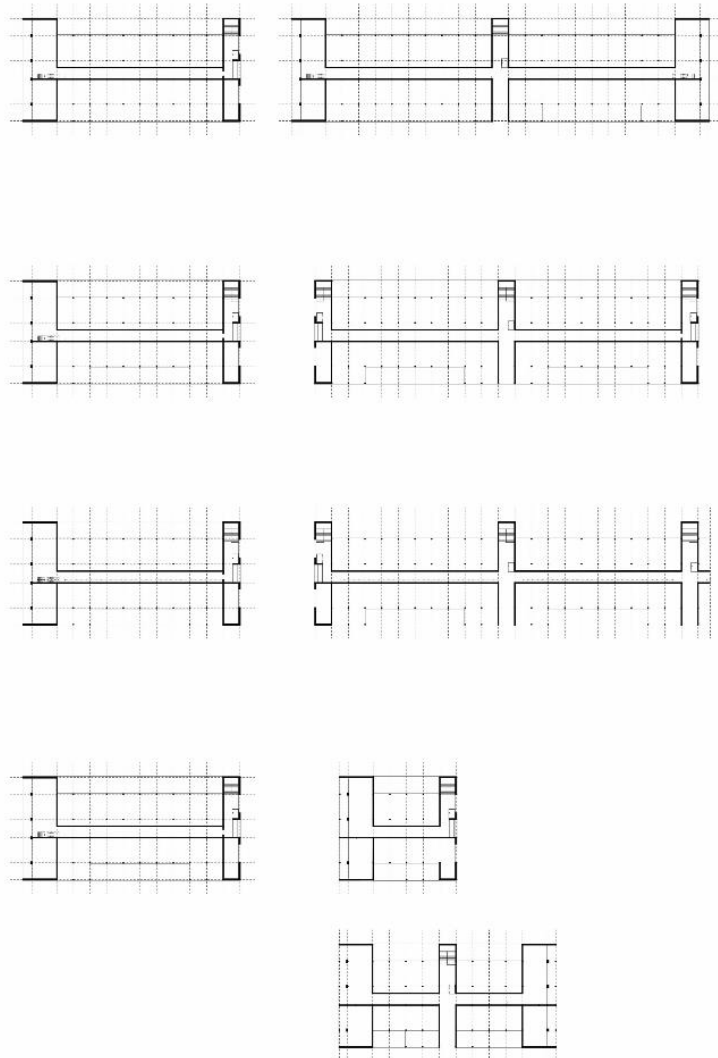

Slika 4. Shema varijacija i modularnosti objekta

\subsection{Ušteda energije i postizanje prijatne atmosfere}

Zbog visoke temperature $\mathrm{u}$ Africi, posebno u letnjem period, morali su da se razrade sistemi hlađenja, što je podrazumevalo sličan sistem kao na objektima koji se nalaze na jugu Španije.

\subsection{Arhitektonsko oblikovanje objekta}

Kada pomislimo na Afriku, osetimo pastelne tonove tamno braon, krem i narandžastu zemlju sa visokom travom i vodenim površinama. Osetimo mir praznine i savršeno mesto da upoznamo sebe i preispitamo svoj život. Osetimo toplotu i zalazak sunca u svim slojevima narandžaste i crne obrise Afričkog drveta, Akacije. Pri projektovanju objekta važno je da se svi ovi elementi ne izgube. Objekat treba da bude neupadljiv, nenametljiv i da se uklapa u prirodno okruženje, kao da tu pripada. Arhitektura treba sa prirodom koja je okružuje da gradi jednu neodvojivu celinu, slike 5, 6 i 7 .

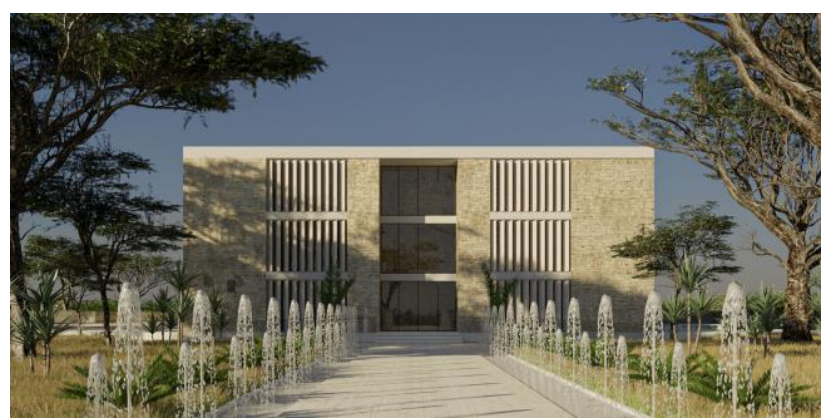

Slika 5. Render eksterijera/prilaz objektu

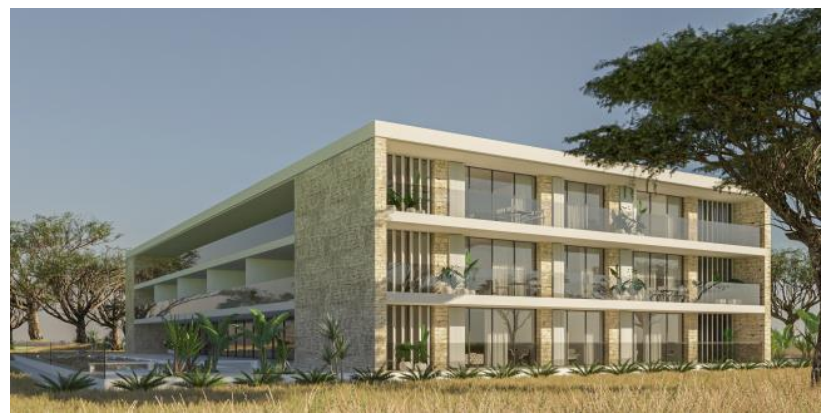

Slika 6. Render eksterijera jugozapadni izgled)

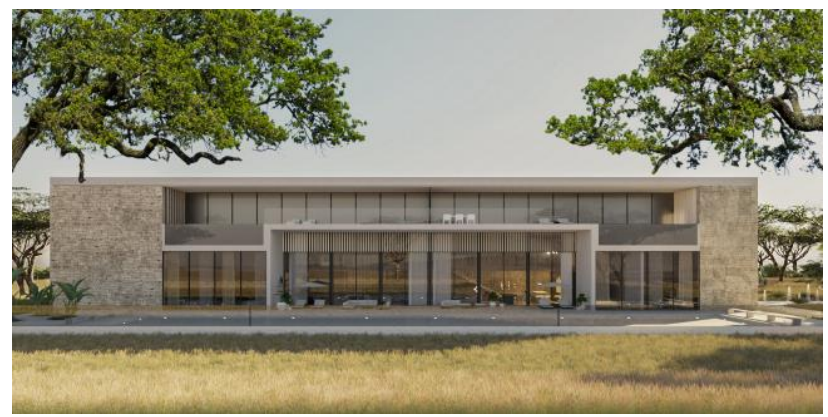

Slika 7. Render eksterijera/istočni izgled

\subsection{Dizajn enterijera}

Enterijeri svakog stana su razvijeni arhitektonski, koristeći unikatni nameštaj koji je dizajniran za ove stanove i kolekcije luksuznog nameštaja iz Aleksandra kolekcije iz Španije i Covet grupe nameštaja iz Portugala. Osnovni cilj jeste da se pokaže da ispravnim izborom nameštaja možemo da postignemo osećaj luksuza, bez obzira na to koliki stan imamo.

Ukoliko je reč o luksuznoj arhitekturi, funkcionalnost je na prvom mestu, a ona se od običnih prostora treba razlikovati po izboru materijala (kvalitetniji materijali) i načinu na koji su rešeni detalji i kako je svaki komad nameštaja dizajniran. U stanovima se koristi nameštaj Covet Group, Alexandra coleccion i slike iz kolekcije "Entropy" [2] umetnice Danijele Gruban. 
Stanovi 1 i 2 imaju isti raspored prostorije, samo su u ogledalu, slika 8 .

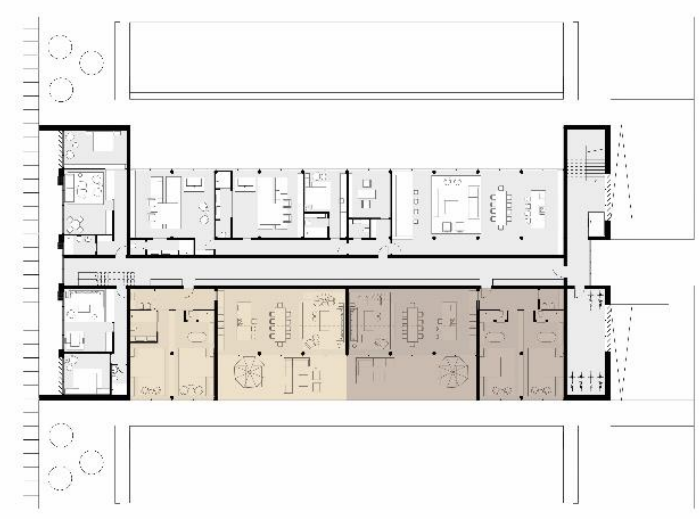

Slika 8. Osnova prizemlja/stan 1- desno/ stan 2- levo

Stan 1 inspirisan je klasičnom arhitekturom grčkog Partenona. Uz kamen u enterijeru sedra je izabrana za stepenište, kuhinju i komodu. Kuhinja je posebno dizajnirana za ovaj prostor. Osnovni materijali su sedra i hrast ofarban u crnu mat boju. Kuhinjsko ostrvo na sebi ima kanaliće, kao kanelure na dorskom stubu što je primenjeno i na kuhinji. Takođe, saksija predstavlja kapitel dorskog stuba, koji je okrenut obrnuto. Nameštaj je korišten iz kolekcije "Alexandra coleccion" [3].

Stan 2 inspirisan je Symphony kolekcijom kuće nameštaja Boca do Lobo, Covet Group [4] iz Portugala. U odnosu na njihovu kolekciju kreirane su kuhinja i zvučnik, uz inspiraciju iz auto industrije i finih neprekidnih linija koje veoma privlačno izgledaju.

Stan 3 inspirisan je neoklasicizmom, radovima Marcija Kogana [5] i Peter Zumthorovim termama u Valsu [6] (hotel u Valsu koji je u sklopu kompleksa), slika 9.

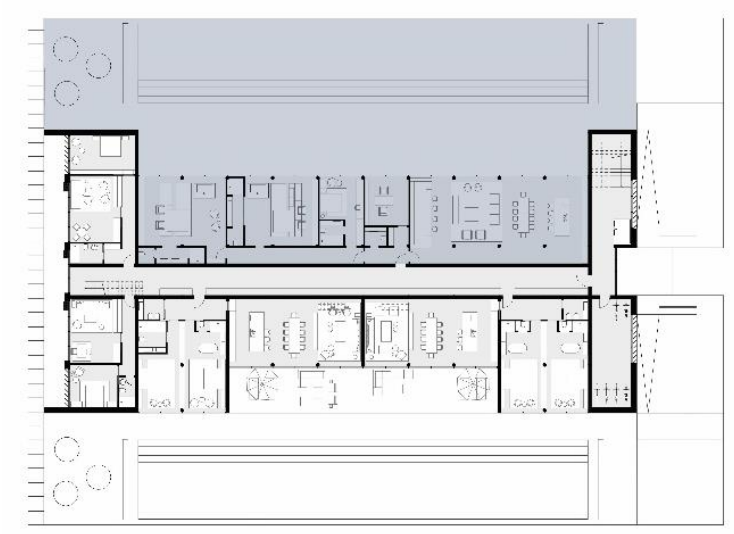

Slika 9. Osnova prizemlja/stan 3

\section{ZAKLJUČAK}

Kroz rad je ispitivano koje su osnovne vrednosti luksuzne arhitekture kroz istoriju i period moderne arhitekture i na koji način se to danas može inkorporirati u objekte.
Takođe, izuzetno važna tema jeste pomiriti svetove, istok i zapad, duhovni i materijalni svet arhitekture i pronaći način da zapadnoevropskim objektima udahnemo istočnu atmosferu. Pored toga, da u čvrste, nepromenjive objekte unesemo fleksibilnost $\mathrm{i}$ ispitamo kada objekat koji je fleksibilan i organizovan rasterski gubi svoju fleksibilnost.

Odgovor se krije u arhitektonskim elementima. Ukoliko su arhitektonski elementi efemerni i lako zamenjivi, onda fleksibilnost ostaje, ali ukoliko su trajni (kao što je pokazano na primeru dodavanja bazena $\mathrm{u}$ objekat) fleksibilnost organizacije se gubi ili postaje redukovana. Važno je bilo osmisliti objekat koji je modularan i koji svojom različitom organizacijom obrazuje veliki broj varijacija. Kada imamo objekat koji je rasterski od početka osmišljen, jako je jednostavno načiniti varijacije na temu. Još jedna od tema rada bila je načiniti luksuzne enterijere i pokazati da nije važno toliko kolike kvadrature je prostor, ukoliko se arhitektonski kvalitetno osmisli, može savršeno da zadovolji čovekove potrebe.

\section{LITERATURA}

[1] Espacio y tiempo en composicion arquitectonica, Rosa Cervera

[2] https://www.instagram.com/danijelagrubanart/

[3] https://www.coleccionalexandra.com/en

[4] https://covetgroup.com/

[5] https://studiomk27.com.br/

[6] https://vals.ch/erleben/erholung/therme-vals/

\section{Kratka biografija:}

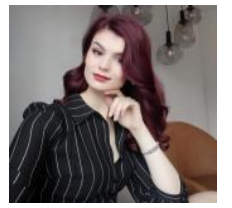

Milica Gruban rođena je u Prijedoru 1995. god. Gimnaziju Sveti Sava u Prijedoru završava 2014, nakon čega upisuje Osnovne studije arhitekture na Fakultetu tehničkih nauka u Novom Sadu. Na trećoj godini odlazi u Španiju na razmenu studenata, gde na španskom i engleskom polaže sve predmete. Za završni rad na osnovnim studijama uzima temu Ekstenzija Esquivell naselja u Sevilji. 2019. završava osnovne studije prosečnom ocenom 9.38 i upisuje master na Fakultetu tehničkih nauka, smer Dizajn enterijera.

kontakt: milica95gruban@gmail.com 